Article

\title{
Evaluating Farmer Attitudes and Knowledge on Reducing An- timicrobial Use in Dairy and Sheep Farms in New Zealand
}

\author{
Peter Moono $^{1 *}$, Skye N. Fruean ${ }^{1,2}$, Debra McCorkindalea ${ }^{1}$ and Mark A. Bryan ${ }^{1,3}$ \\ 1 VetSouth Ltd, P.O. Box 12, Winton, Southland, New Zealand; petermoono@yahoo.co.uk and pe- \\ ter.moono@vetsouth.co.nz (P.M.); debram@vetsouth.co.nz (D.M.); markb@vetsouth.co.nz (M.B.); \\ debram@vetsouth.co.nz (D.M.). ORCID: Peter Moono https://orcid.org/0000-0001-9002-1339. \\ 2 Health Australian, Government Department of Agriculture and Water Resources sources, 4108, Cairns, \\ Queensland, Australia.skye.fruean@agriculture.gov.au (S.F.). \\ 3 Institute of Veterinary Animal and Biomedical Sciences, Massey University, Private Bag 11 222, Palmerston \\ North, 4442, New Zealand. markb@vetsouth.co.nz (M.B.); \\ * Correspondence: peter.moono@vetsouth.co.nz; Tel.: +64 272553421 (P.M.)
}

Simple Summary: There is increasing public demand on livestock producers to reduce antimicrobial use (AMU) in food animals. The demand stems from concerns about potential antimicrobial resistance that could originate from food animals. We surveyed dairy and sheep farmers to assess their attitudes towards reducing AMU. This study has shown that sheep farmers were more concerned about antimicrobial resistance than dairy farmers.

The dairy and sheep farmers sourced most of their advice from veterinarians, the livestock industry and their colleagues. This study has shown that livestock farmers showed varied concerns about AMU. This study suggests that knowledge gaps in farmers may best be filled by veterinarian input.

\begin{abstract}
This work examines dairy and sheep farmer attitudes toward antimicrobial use (AMU) in New Zealand. There is increasing public demand on livestock producers to reduce AMU in livestock. The demand stems from concerns about potential antimicrobial resistance (AMR) that could originate from food animals. There is limited practical data on farmer knowledge of AMU. An electronic survey was sent to dairy $(n=378)$ and sheep farmers $(n=551)$. Seventy-six dairy farmers $(20 \%, n=76 / 378)$ returned the survey. Dairy farmers (69\%) showed low levels of concern about antimicrobial resistance and awareness of the need to reduce AMU. Additionally, 76\% of dairy farmers didn't think it was possible to reduce AMU. Thirty-nine sheep farmers $(7 \%, 39 / 551)$ returned the survey. $76 \%$ of sheep farmers were supportive of restricted use of AMU. The dairy and sheep farmers sourced most of the advice from veterinarians $(>90 \%)$, the livestock industry $(>80 \%)$ and their colleagues $(>70 \%)$. This study shows that farmers showed varied concerns about AMR and AMU. Moreover, sheep farmers were more amenable to increased restriction on AMU than dairy farmers. This study suggests that knowledge gaps in farmers may best be filled by veterinarian input.
\end{abstract}

Keywords: Antimicrobial use; knowledge; farmer-attitude; dairy-farmer; sheep

\section{Introduction}

Antimicrobial resistance (AMR) is one of the most significant global threats to human health $[1,2]$. The development and the resultant transmission of AMR are complicated [3]. The association between antimicrobial use (AMU) and AMR in livestock has been extensively studied [2, 4, 5, 6, 7, 8, 9]. In New Zealand [10], like the UK [5], AMU is strictly managed by veterinarians in collaboration with their livestock farmer clients. After a veterinarian gives a prescription, farmers may purchase and use antimicrobials without the veterinarian present. New Zealand farmers [10] make on-farm decisions re- 
garding the type of antimicrobials to use. Therefore, it is essential to understand New Zealand farmers' decision-making process because they are directly involved in the AMU on farms.

The inappropriate use of antimicrobials is the primary driver of antimicrobial resistance in both animal and human health in the world $[2,4,6,7]$. There has been a strong belief that zoonotic transfer of bacterial AMR is occurring from animals to humans [12], although there is a paucity of proven data that supports this hypothesis $[4,21]$. The reverse zoonotic transmission (zooanthroponosis) of the AMR transmission has been proposed $[8,14]$, although it is not widely considered. The main source of AMR in humans in New Zealand has been hypothesized human origin of AMU [3,43]. Other potential routes of transmission of AMR have been suggested as originating from animal food products, direct contact, and environmental transmission [4, 15, 16, 17, 18]. In some dairy herds, the blanket use of dry cow therapy has been used [3]. In the New Zealand livestock industry, there is currently a shift towards less use of blanket dry cow therapy and also using critical antimicrobials as has been described in the $2015 \mathrm{New}$ Veterinary Association guidelines on the prudent use of antimicrobials [19].

Global AMU in animals is expected to increase by at least $70 \%$ by 2030 [18]. Antimicrobials are now increasingly found in large quantities in human-made environments such as sewage and wastewater treatment plants [12] and terrestrial, freshwater, and marine environments [21,4]. Moreover, antibiotic pollution is poorly regulated on both local and global scales [21,4]. Most of the pathogens associated with mastitis in cows, such as Staphylococcus aureus and Escherichia coli (E. coli), are also detected in medical settings, carrying resistance genes against multiple classes of antibiotics abroad [18]. The most well-known of these is methicillin-resistant S. aureus (MRSA) and extended-spectrum beta-lactamases carrying E. coli. Although MRSA is not prevalent in New Zealand cows, it has been reported [3].

Many researchers have described on-farm AMU monitoring in dairy herds worldwide [8, 22, 23, 24, 25] and New Zealand [3, 26]. However, limited studies have investigated farmer attitudes and knowledge towards AMU in the dairy and red meat industry in New Zealand. To achieve a significant reduction in AMU in New Zealand, there is a need to understand the underlying drivers of AMU in livestock producers. This work aimed to gain insight into farmer perception of AMU and identifies factors that could be a barrier to AMU reduction at the farm level. 


\section{Materials and Methods}

\subsection{Farmer Attitude Surveys}

The population was defined as dairy and sheep farmers who were clients for VetSouth Ltd for at least two years before the 2017/18 season and resided in the south Otago region. The criteria used to select email addresses from the VetSouth Ltd large animal database was based on active clients two years before the 2017/18 season. Following consent, an electronic survey (survey monkey) was mailed out to dairy $(\mathrm{n}=378)$ and $(n=551)$ sheep farmers on their attitudes on the use of antimicrobials (Table 1). The electronic survey was divided into two sections, first, information about the source of advice to farmers, and second, their perceptions of antimicrobial use.

Each respondent went through a series of general questions. Some included information regarding how they valued animal welfare, economic data, veterinary advice, industry advice, lameness issues, production diseases such as mastitis and potential treatment.

Additionally, data requested included calf rearing diseases, potential treatments, and information about the prudent use of antimicrobials on the farm (selective dry cow therapy vs. blanket dry cow therapy). Other data requested include contamination of animal products by antimicrobials, data about critical antimicrobials used in human health, when should antimicrobials be available (also who should be in charge), and whether they were interested in antimicrobial use reduction or not. The respondents described the management tools they used on a 10 point Likert scale (Table S1). Respondents rated their views on a 1-10 Likert scale depending on the question. If the answer was agreed, then $(1=$ strongly disagree and $10=$ strongly support $)$. All these were closed questions except for a few open-ended questions toward the end of the survey, asking farmers to provide demographic data such as age, gender, education level, farm location, and herd size. Each variable was available for analysis if it had at least 20 percent responses except for apriori variables.

\subsection{Statistical Analysis}

The data were analysed using the descriptive techniques developed by Likert [27] and implemented in the $\mathrm{R}$ package Likert version 1.3 .5 and using the $\mathrm{R}$ statistical software version 4.0.4. [28].

\section{Results}

\subsection{Dairy Farmer Survey}

Seventy-six dairy farmers $(20 \%, 76 / 378)$ returned the survey. Of these, $52 \%(n=40)$ were male, $22 \%(n=17)$ female, and $25 \%(n=20)$ of unknown gender (Table 1$)$. The lowest education level among the dairy farmers was a primary school certificate, and the highest, a postgraduate degree (Table 1). More male respondents had a higher education (Master's degree, $n=10)$ than females (Master's degree, $n=3)$. Females $(n=17,30-60$ years) were younger than male respondents $(n=40,30$ to $>=60)$. More male respondents $(n=10$, $>1000$ cows) had bigger herd sizes compared with female respondents $(n=2)$. 
Table 1. Demographic indices of the dairy and the sheep farmers by gender.

\begin{tabular}{lcc}
\hline Demographic variable & $\begin{array}{c}\text { Dairy farmers, } \boldsymbol{n}(\mathbf{\%}) \\
\mathbf{2 0 1 7 / 2 0 1 8}\end{array}$ & $\begin{array}{c}\text { Sheep farmers, } \boldsymbol{n}(\mathbf{\%}) \\
\mathbf{2 0 1 7 / 2 0 1 8}\end{array}$ \\
\hline Survey respondents & 77 & 39 \\
\hline Gender & $17(22)$ & $4(10)$ \\
Female & $40(52)$ & $16(41)$ \\
Male & $20(25)$ & $19(49)$ \\
Unknown & & $1(3)$ \\
\hline Age & $6(8)$ & $7(18)$ \\
$\leq 30$ & $25(19)$ & $3(8)$ \\
31 - 40 & $14(18)$ & $4(10)$ \\
41 - 50 & $16(21)$ & $6(15)$ \\
51 - 60 & $6(8)$ & $18(46)$ \\
$>60$ & $20(26)$ & \\
Unknown & & $7(18)$ \\
& & \\
\hline Education & $13(17)$ & $4(10)$ \\
Bachelor's degree & $13(17)$ & $2(5)$ \\
Diploma & $9(12)$ & $7(18)$ \\
Certificate & $7(9)$ & \\
Secondary school (year 13) & & \\
& &
\end{tabular}




\begin{tabular}{lcc}
\hline Master's degree & $13(17)$ & $1(3)$ \\
Unknown & $20(26)$ & $18(46)$ \\
\hline Herd and or flock size & & \\
0 to 250 & $1(1)$ & $2(5)$ \\
251 to 500 & $17(22)$ & $2(5)$ \\
501 to 750 & $16(21)$ & $2(5)$ \\
751 to 1000 & $9(12)$ & $15(38)$ \\
$>1000$ & $12(16)$ & $18(46)$ \\
Unknown & $22(29)$ & \\
\hline
\end{tabular}




\subsubsection{Source of Advice Dairy Farmers on disease control}

The majority of the dairy farmers sourced most of advice from their veterinarian (Fig. 1). Veterinary advice was the most approved source $(n=76,99 \%)$ in the survey, dairy industry advice $(87 \%)$ and from their peers $(75 \%)$ (Fig. 1). The majority of the dairy farmers were aware that antimicrobials were essential in improving animal welfare $(100 \%)$, as shown in the Figure 1.

The biggest problems which farmers faced as identified in this study were scours in calves (38\%), followed by metritis/endometritis (13\%) and mastitis (8\%) (question 3 of the survey) (Fig. 1).

The proportion of farmers that identified management practices as way to prevent herd problems were as follows; lamness $(81 \%$ )as the highest problem they could solve using better management tool followed by metritis/endometrritis (73\%) and scours (69\%) (Fig. 1). 


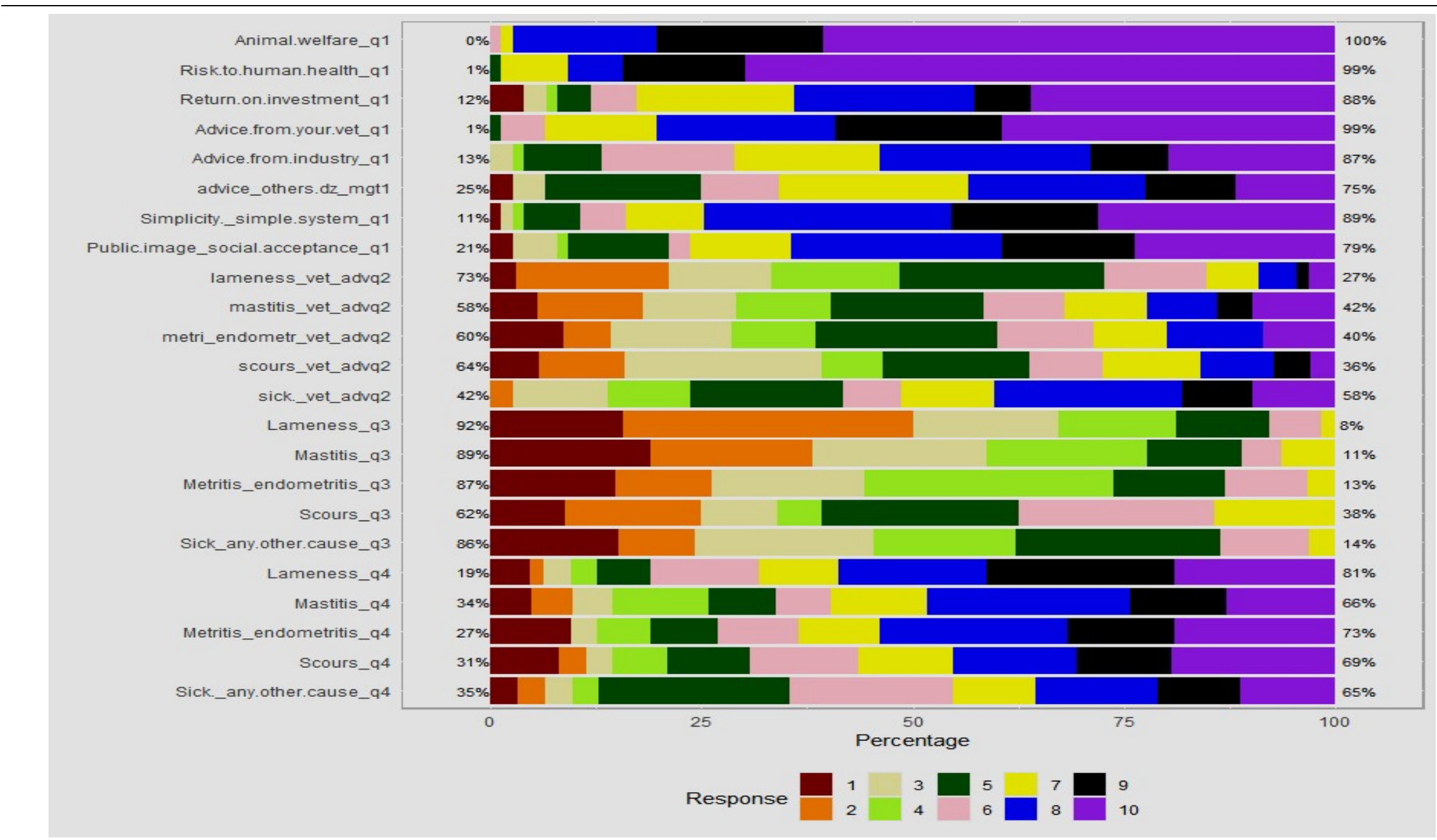

Figure 1. Percentage approval of sources of advice by the dairy farmers (season, 2017/2018). The percentage 10 points Likert scale (where $1=$ strongly disagree, $10=$ strongly agree) . 


\subsubsection{Attitudes towards Antimicrobial Use by Dairy Farmers}

Fig 2 shows why dairy farmers thought it would be good to reduce antimicrobial use in their herds. In this survey, seventy-one per cent $(n=58)$ of dairy farmers thought that antimicrobials such as penicillin were effective at treating mastitis, followed by lameness (59\%), and metritis/endometritis (48\%) (Fig. 2).

The following proportion of farmers who thought that other therapies were effective at treating conditions by using pain killers, anti-inflamatories and vaccinations were as follows; lameness (45\%), followed by mastitis (33\%) and sours (26\%) (Fig. 2).

The propotion of farmers showing how frequently they used management practices to prevent problems in the herds are tabulated below; lameness (69\%), followed by metritis endometritis (67\%) and mastitis (57\%) (Fig 2). The frequency by which farmers would use antimicrobials such as penicillin to treat cows at their farms is as follows; mastitis ( $82 \%$ ), followed by lameness (55\%) and metritis/endometritis (48\%) (Fig 2). The frequency by which farmers used other therpies apart from antimicrobials were as follows; lameness (37\%), mastitis (29\%) and scours (24\%).

There were $81 \%$ of dairy farmers who agreed that they were interested in reducing AMU (partaining to question 10, Table S1). Respondents were also supportive that there were better ways to preventing animals getting sick than use of antimcrobials (58\%) (Fig. 2). Farmers were not supportive of banning or restricting use in animals of antimicrobials that are important for maintaining human health (69\%). The majority of farmers (64\%) were supportive of antimicrobials being available more freely from outlets other than from the veterianarians. Additionally, $76 \%$ of farmers didn't think it would be possible to decrease the antimicrobials they used on their farms. A smaller proportion of farmers supported that antimicrobials should remain restricted and be accessible only from the veterinarians (59\%). Only 31\% of respondents approved the blanket use of drycow therapy on mastitis control (Fig. 2).

Dead cows were disposed of in the following manners; incineration on farm $(n=16 / 77,21 \%)$, petfood company or dead cow collectors $(n=15 / 77,19 \%)$, fed to own dogs $(n=10 / 77,13 \%)$, other $(n=19 / 77,25 \%)$ and unknown $(n=17 / 77,22 \%)$.

Milk contaminated with antimicrobials were disposed in the following ways; down the drain ( $n=18 / 77,23 \%)$, fed to replacement calves $(n=16 / 77,21 \%)$, fed to other stock $(n=13 / 77,17 \%)$, other $(n=14 / 77,18 \%)$ and unknown $(n=16 / 77,21 \%)$. This is the potential sources for environmental contamination by antimicrobials 


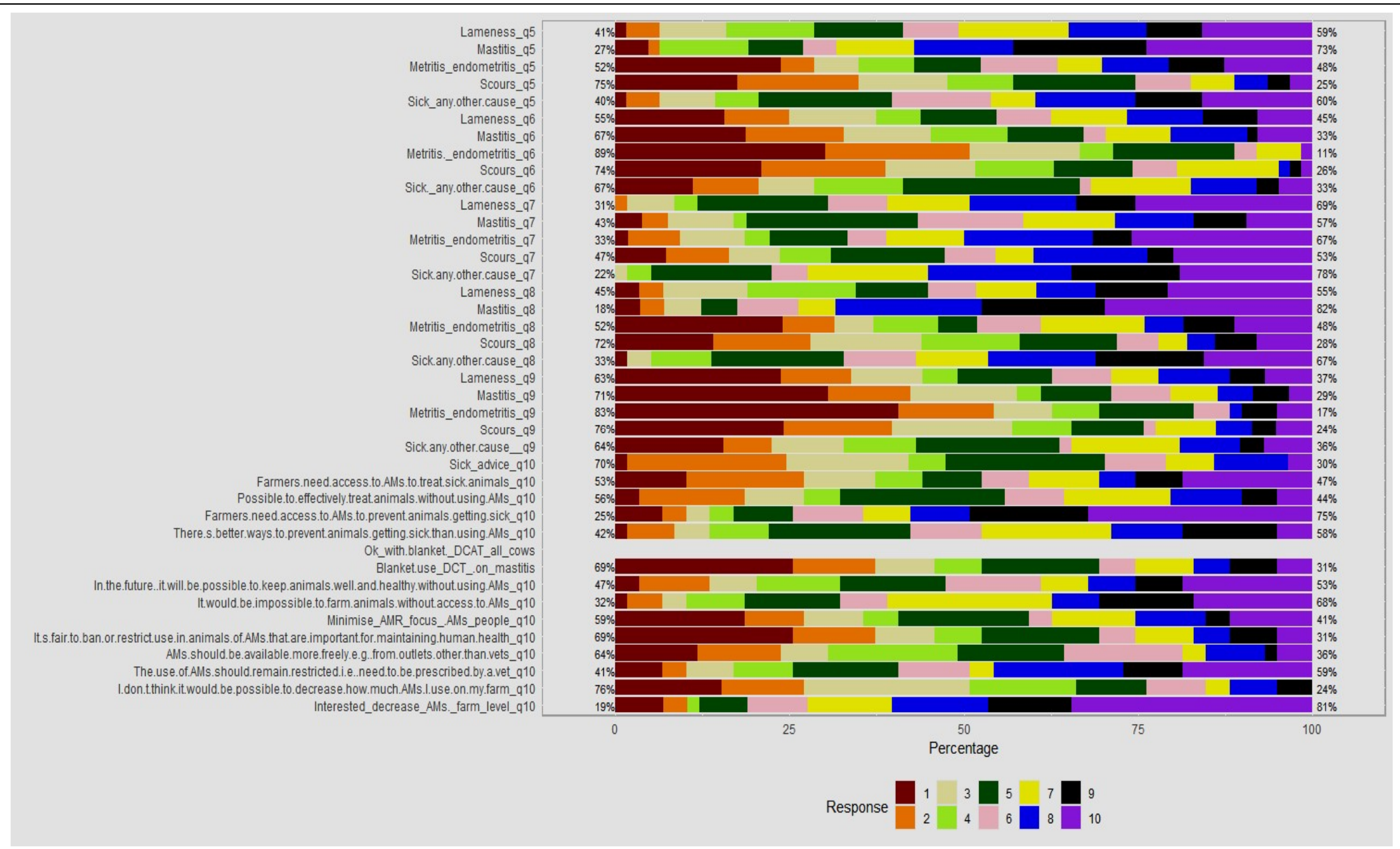

Figure 2. The attitudes and knowledge of the dairy farmers on how to use antimicrobials (season, 2017/2018). The percentage10 points Likert scale (where $1=$ strongly disagree, $10=$ strongly agree). Note: AMs is Antimicrobials; DCAT is dry cow antimicrobial therapy; DCT is dry cow therapy; AMR is antimicrobial resistance. 


\subsection{Sheep Farmer Survey}

Thirty-nine sheep farmers returned the survey $(7 \%, 39 / 551)$. Of these, $41 \%(n=16)$ were men, $10 \%(n=4)$ women, and $49 \%(n=19)$ were of unknown gender. The lowest education level among the sheep farmers was a Secondary school (year 13) and, the highest, a postgraduate degree (Table 1). More male respondents had a higher education (Master's degree, $n=1)$ than females (Master's degree, $n=0)$. Females $(n=3,31-50$ years) were younger than male compared with males $(n=15,31-60,>=60)$. More male respondents ( $\mathrm{n}=14,>1000$ sheep) had bigger flock sizes compared with female respondents $(n=1)$.

\subsubsection{Source of Advice by the Sheep Farmers on disease control}

The majority of the sheep farmers were sourced most of their advice from their veterinarian (Fig. 3). Veterinary advice was the most approved source ( $n=39,97 \%)$, followed by industry advice $(n=39,82 \%)$ and from their peers $(n=39,82 \%)$ (Fig. 3$)$. The majority of the sheep farmers were aware that antimicrobials were essential in improving animal welfare $(100 \%)$, as shown in the Figure 3.The major ewe diseases encountered by farmers were metritis/endometritis (20\%) and mastitis (9\%) (Fig. 3). 


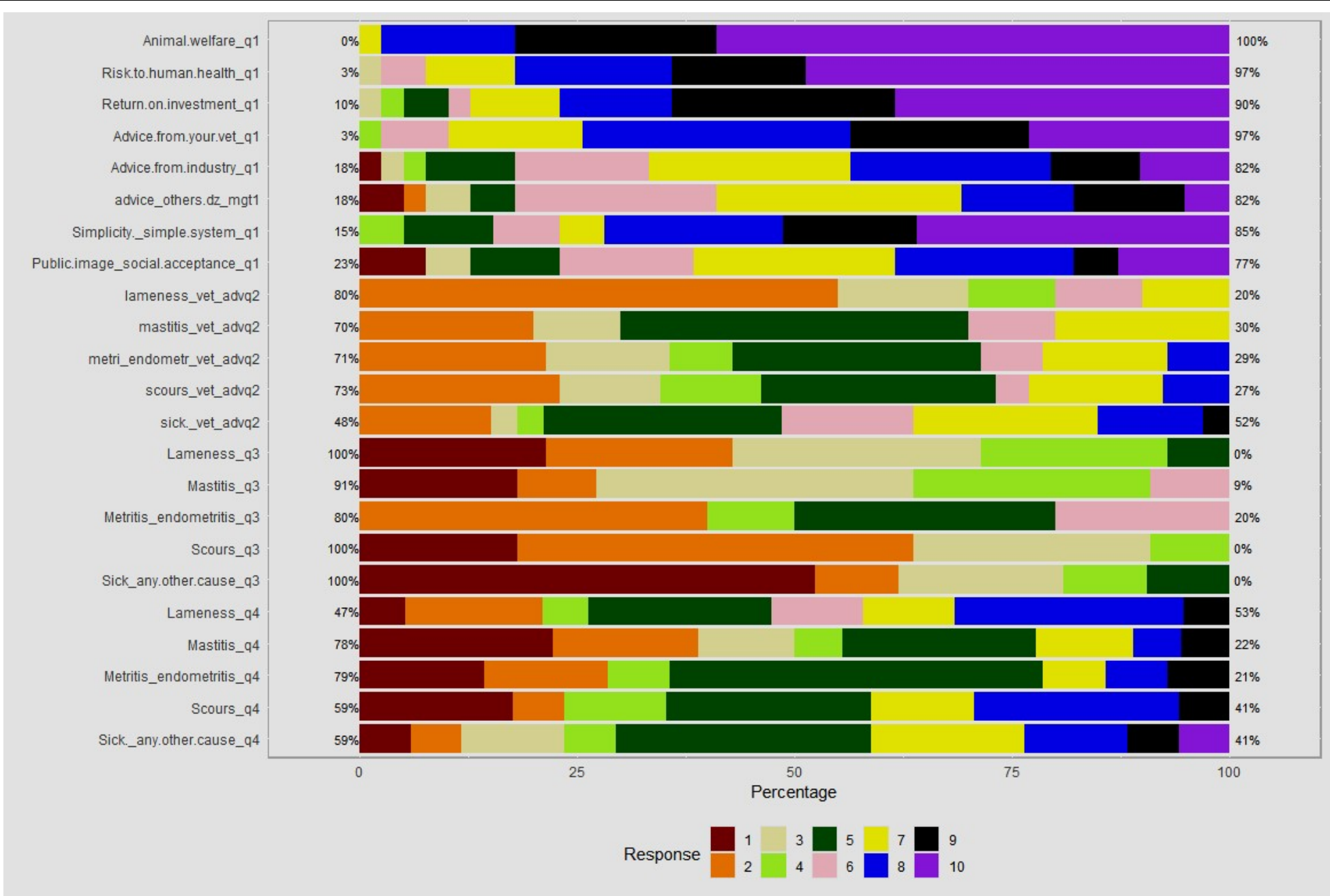

Figure 3. Percentage approval of sources of advice by the sheep farmer sources (season, 2017/2018). The percentage 10 points Likert scale (where $1=$ strongly 2 disagree, $10=$ strongly agree). 


\subsubsection{Attitudes towards Antimicrobial Use by Sheep Farmers}

Farmers who thought that antimicrobials were effective for treating disease conditions on farms were as follows; mastitis (83\%), followed by metritis/endometritis (71\%) and lameness (53\%) (Fig. 4).

Respondents who thought that other therapies (pain killers, anti-inflammatories, and vaccinations) were effective in preventing disease conditions on farms were as follows; scours (53\%), followed by lameness (50\%), and mastitis (44\%) (Fig. 4).

The frequency by which farmers were going to use management practices to prevent disease on farms were as follows; scours (62\%), followed by lameness $(60 \%)$, and metritis/endometritis (12\%) (Fig. 4).

The proportion of farmers and frequency by which they would use management practices in preventing diseases on their farms were as follows; lameness (53\%), followed by scours (41\%) and mastitis (22\%) (Fig. 4).

The proportion of respondents (question 8) that used antimicrobials to treat disease conditions on farms were as follows; mastitis (82\%) followed by lameness $(50 \%)$ and metritis /endometritis (50\%) (Fig. 4).

There were $76 \%$ of sheep farmers that were supportive of antimicrobial being restricted and that only veterinarian were supposed to prescribe antimicrobials. There were $71 \%$ of farmers that were interested in reducing antimicrobial use (Fig. 4). Farmers (75\%) were not supportive of minimising antimicrobial resistance focused on antimicrobials used in the medical settings. The majority of farmers $(86 \%)$ were supportive of antimicrobials being available more freely from outlets other than from the veterinarians. Additionally, 56\% of farmers didn't think it would be possible to decrease how much antimicrobials they used on their farms.

Dead sheep were disposed of in the following manners; incineration on farm $(n=4 / 39,10 \%)$, fed to own dogs $(n=4 / 39,10 \%)$, other $(n=13 / 39,33 \%)$ and unknown $(\mathrm{n}=18 / 39,46 \%)$. 


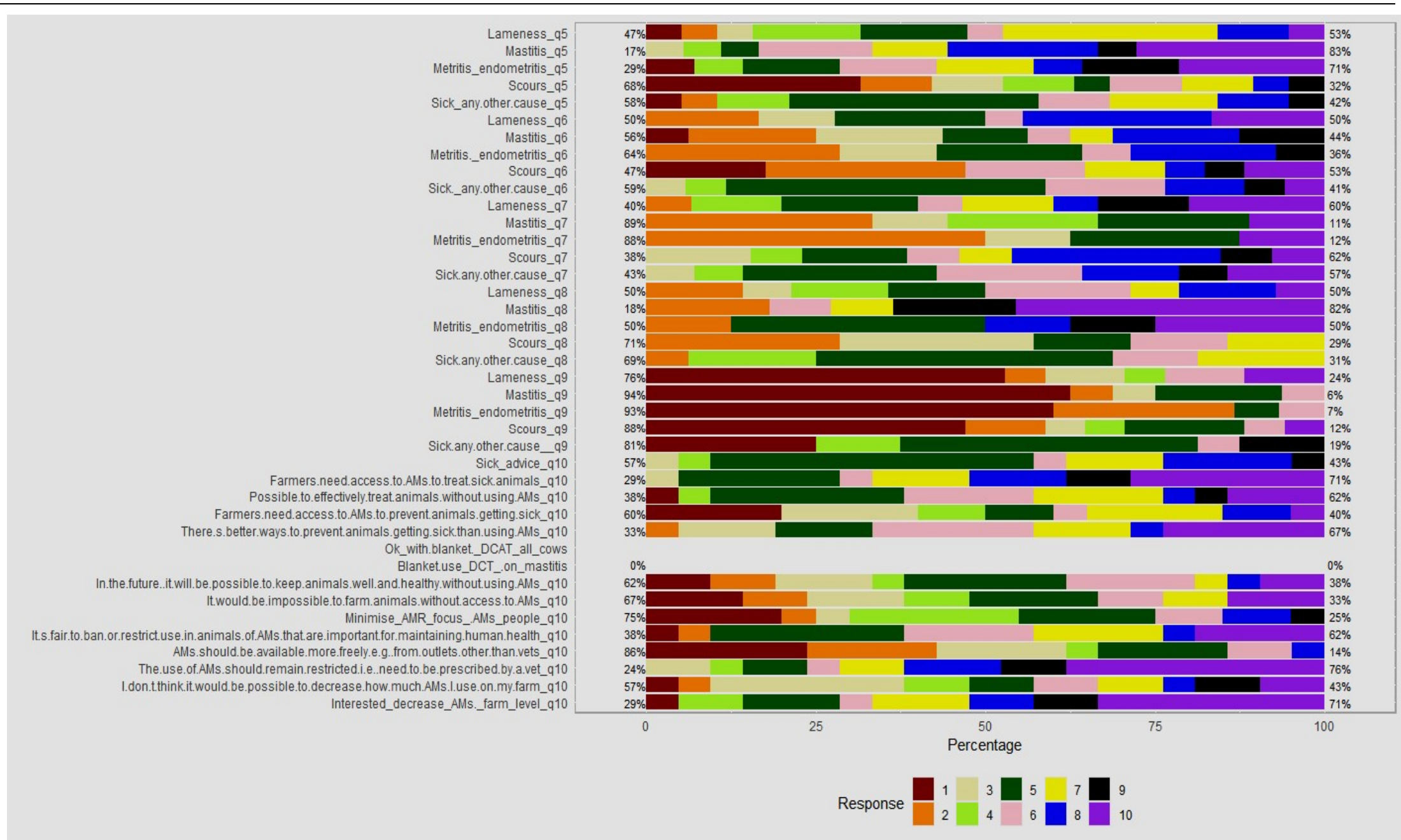

Figure 4. The attitudes and knowledge of the sheep farmers on how to use antimicrobials (2017/2018 season). The percentage 10 points Likert scale (where $1=$ strongly disagree, $10=$ strongly agree). Note: AMs is Antimicrobials; DCAT is dry cow antimicrobial therapy; DCT is dry cow therapy; AMR is antimicrobial resistance 

below.

The most important findings from this survey have been highlighted and presented

- Farmers were more likely to seek advice from their veterinarians, the livestock industry bodies and peers.

- $\quad$ Farmers were interested in decreasing antimicrobial use in livestock

- Farmers recognised antimicrobials as a vital tool for managing the disease on farm

- The belief that access to antimicrobials for the treatment of animals should remain controlled

- Agreeing with the statement that antimicrobials critical for human health should be restricted on the farms

- Understanding that there are other therapeutic options to prevent disease than antimicrobials, and

- Acknowledging that there are other therapeutic options than antimicrobials available for the treatment of disease.

\section{Discussion}

The present study highlights the attitudes and knowledge of a population of dairy $(n=76)$ and sheep $(n=39)$ farmers in South Otago in New Zealand towards antimicrobial use (AMU). Because farmers are involvement in decision making regarding antimicrobial use on farms, understanding their attitudes and knowledge is important when implementing strategies for reducing AMU.

In this study, the dairy and sheep farmers showed high knowledge about the importance of animal welfare (Fig. 1, 2, 3 and 4). This is not surprising because farmers sourced most of their advice from their veterinarians (Fig1 and 3). This finding is consistent with previous studies in New Zealand [10], the UK [29], the USA [30, 31] and Italy [32]. Additionally, farmers identified the livestock industry as the second most trusted source for advice. This is important because the livestock industry bodies and veterinarians work together to achieve improvements required in livestock industry. For example, in 2015, the New Zealand Veterinary Association (NZVA) [19] developed guidelines on the prudent use of antimicrobials in food animals. These guidelines have been adopted by International Dairy Federation in order ensure that farmers, veterinarians, milk processing companies, pharmaceutical companies and regulators were aware of the need for food safety. Although the NZVA guidelines are specifically important to New Zealand veterinarians, it is evident that information is targeted at the whole food supply chain. Although New Zealand is among the few countries that use the lowest amount of antimicrobials in food animals [3], there is still room to reduce AMU further down. The NZVA has an ambitious plan to end the use of antimicrobials for maintenance of animal health and wellness [19]. In this study, we found quite a lot of concerning attitudes towards reduction of AMU and AMR. Both dairy and sheep farmers were not concerned about AMR (Fig 2 and 4). Additionally, dairy farmers did not support a ban or restriction of critical antimicrobials used in human medicine compared with sheep farmers. Both dairy and sheep farmers were of the view that antimicrobial were supposed to be freely accessible from outlets other than veterinary centres. Dairy $(76 \%)$ and sheep (57\%) farmers thought that it was impossible to decrease AMU on farms. In this survey, only $31 \%$ of dairy farmers suggested that they would use DCT on cows with mastitis (Fig 2). However, there were no farmers that wanted to use DCT in all herds of cows. Although both dairy and sheep farmers said they were interested in reducing AMU, it appears that their attitudes did not support that suggestion. The reasons for farmers why farmers did not see the importance of reducing critical AMU and AMR are unclear. It is plausible that farmers would want to have access to antimicrobials from other source than the veterinary clinic probably based on the costs. This suggests that if farmers were to achieve 
significant reduction in AMU in food animals, policy makers should target veterinary input on prudent use of antimicrobials.

Studies have shown that suboptimal herd management could increase livestock susceptibility to bacterial infections and disease [30, 33, 34]. Veterinarians believe that improving herd and environmental management could help farmers reduce the dependence on AMU thereby reducing disease by preventative means [32]. In this study, dairy farmers chose lameness (81\%) and metritis/endometritis (73\%) as diseases where management practices were effective (Fig 1) compared to sheep farmers who chose lameness (53\%) and scours (41\%). Dairy farmers chose mastitis (73\%) and lameness (59\%) as disease conditions for which antimicrobial therapy were effective (Fig 2) whereas sheep farmers chose mastitis (83\%) and metritis/endometritis (71\%) (Fig 4). It is not clear when antimicrobial therapy is indicated for lameness in either dairy cows or sheep. It is generally accepted that adequate hoof trimming and other manage practices that includes changing nutrition and improved genetic breeding have been suggested as adequate preventative treatment. It seems quite odd if dairy (59\%) dairy farmers belied that it was alright to use antimicrobial therapy for treatment that requires at most preventative measures. These scenarios above suggest that both dairy and sheep farmers required some additional training to understand the underlying problems at the farms that can be addressed to reduce AMU. Although our practice provides each farmer with a key veterinarian who forms a relationship with the farmers it appears that there is likely a discrepancy between what a veterinary advice and what farmers do. The relationship between the way farmers and veterinarians interact could be an area that may need an improvement.

For some conditions such as cow lameness, mastitis, metritis, endometritis, and scours in calves, the respondents were less likely to seek veterinary medical advice (Fig 1 and 3). A study in Canada found that farmers used previous experiences of similar cases they encountered and the type of AMU as a determinant of the type of antimicrobial they were going to use when a similar case came up [35]. This may suggest either those farmers have a fair experience in dealing with clinical mastitis or that they have had consistent advice from their veterinarians on how to manage the disease impact on their cattle herds. This is likely due to many factors, such as interactions between veterinarians and farmers. The other determinant for farmers not to seeking advice from veterinarians on diseases such as mastitis was likely the cost associated with a veterinary consult compared to culling a cow. The leading cause of culling cows is clinical mastitis [36]. Studies have shown that time limitations during a veterinary consult and lack of farmer interest in the subject is some of the drivers for poor disease management on farms [32, 37]. In the study population, the time limiting factor was unlikely to be an issue because farmers have free access to their key veterinarian. Further research is needed to identify factors that affect New Zealand farmers towards failure to seek advice for some livestock conditions.

The drivers of the willingness by the respondents to decrease the use of antimicrobials are complex. For example, dairy farmers (>74\%) were more likely to reduce the use of antimicrobials based on the public image. The proportion of sheep farmers that were likely to reduce antimicrobial use based on the public image was slightly lower on average $(67 \%)$. Different factors likely drive the social determinants for change in both industries. The discrepancies between wanting to achieve something and how much achievement is attained by a client have been described elsewhere $[38,39]$. The effects of public perceptions of the industry are not the only factors that could drive change. Future research should use more robust methods to identify determinants that could accurately identify motivation for change among livestock farmers.

The majority of dairy (81\%) and sheep farmers ( 71\%) were interested in decreasing AMU (Fig 2 and 4). A study in New Zealand has found that some farmers exerted influence on the prescription of antimicrobials (45/206; 22\%) [10]. Similarly, studies abroad have shown that farmers expected veterinarians to include antibiotics in the treatment plan even when they were not indicated [40, 41, 42, 43, 44]. In general, in New Zealand, 
antimicrobial prescription by veterinarians are based on clinical and laboratory diagnosis of infection ( $\mathrm{n}=168 / 206,82 \%)$ [10]. Over $75 \%$ of all respondents believed that the source of advice would approve them reducing the use of antimicrobials. This is important because the New Zealand livestock industry is moving towards implementing the reductions in AMU. Studies abroad have shown that veterinarians with fewer years in clinical practice showed higher interest in understanding the potential burden of antimicrobial resistance in livestock in the Netherlands [42] and the USA [30]. The findings in this study suggest that at least $20 \%$ of farmers were not interested in reducing AMU.

There has been a policy shift in the New Zealand livestock industry towards reducing blanket use of antimicrobials in food animals [45]. Given the high favourably response rates on the attitudes toward prudent use of AMU in this study, it may suggest that farmers favourably followed the veterinarian advice. This work indicates that perception and knowledge of AMU among farmers can improve if they received consistent advice from veterinarians (Fig. 1 to 4). The patterns of attitudes towards AMU between the dairy and sheep farmers were not dissimilar, as shown in (Fig. 1 to 4). This is not surprising given the small geographic area where these farmers were based. These findings in this study are consistent with those reported by others [10, 29]. These findings in this study were not unexpected because most farmers surveyed had a high level of education (minimum primary school certificate and maximum with postgraduate qualification) (Table 1). Additionally, the gender, age of respondents and herd/flock sizes were evenly distributed among dairy and sheep respondents (Table 1). What was unusual about these findings was the lack of support for restricted access to antimicrobials critical to human health by the dairy (69\%) farmers (Fig. 2). However, sheep (76\%) farmers supported the restricted access to antimicrobials critical to human health (Fig. 4). These disparities in attitudes between two farming systems in attitudes towards AMU and AMR are concerning. A postal survey about antimicrobial prescription in livestock in France showed a high variation in AMU per animal species [8]. Similar to the French study, there was a high variation in the response rate between the dairy and the sheep farmers by question type. The fact that these ideas for change appear to have been influenced by veterinary input suggests that in the future, policymakers must engage the trusted sources of advice at the very earliest possible time to achieve AMU reduction.

Although the risk of methicillin-resistant S. aureus (MRSA) has been described as low in New Zealand [3], practices such as disposing of waste milk in drainages (23\%) or fed to other livestock (21\%) may suggest that the risk is likely higher than has been estimated. If milk contaminated with bacteria carrying antibiotic resistance genes was drained in the environment where edible wild life like ducks swim or in vegetables, there is a possibility of antimicrobial resistant pathogens gaining access to humans food chain. These practices could also lead to dispersal of novel infectious pathogens within and between farms. This is an important area that is likely where veterinarians can provide guidance to the farmers to prevent environmental contamination with antibiotic resistant pathogens. Similar disposal methods of carcasses of cows or sheep by feeding carcasses to dogs as food is a likely routine by which antibiotic resistant could gain access to human population from the environment.

In this study, we did not evaluate the impact of the herd size on the influence of AMU. However, a study in the UK found that high milk-producing dairy herds were more likely to reduce antimicrobial use in their herds for many reasons [29]. The first reason was that it was economically advantageous to reduce spending money on buying antimicrobials. Second, these high producing farmers were focusing on the future when AMU restrictions were likely to be implemented. In New Zealand, both scenarios are possible to be true because the dairy industry is commercially oriented and may be beneficial to farmers.

Studies have shown that results obtained from online surveys provide only a partial understanding of how farmers manage their farms daily [46]. The response rates for both the dairy and sheep farmers were not very high (Table 1). Therefore, the results of this study may not be able to be extrapolated to the farmers who did not respond because we 
have no understanding of why they didn't. Despite the small sample sizes for both surveys, the present study highlights the attitudes and knowledge of livestock farmers in New Zealand towards the AMU on the farm for both the dairy and sheep farmers. In our experience in rural settings, farmers are keen to learn from their peers who have had a similar experience. Although the personal attitudes and peers attitudes have a non-causal relationship [29], studies have shown that interpersonal networks were a widely used method by which farmers acquired knowledge [47, 48, 49]. Jones and colleagues (2015) [29] showed that the most vital driver of farmers in implementing change was their belief that their social network would approve their actions. In our veterinary practice, we have a concept of allocating a farm with a veterinarian with a good relationship with a farmer and understanding the farm dynamics. This way, there is likely that good consistent veterinary advice is available to the farmers in a manner other countries may not provide. The findings in this study support that veterinary advice was still the primary source of advice

This study was limited to respondents who had access to an email and belonging to VetSouth Ltd client list. It is possible that a bias was introduced by not considering a random sample. The total number of dairy client at that time was roughly 400 ; therefore, we gave a chance to almost all clients to participate in the survey. The respondents were also nearly a third of the clients that received the survey. This shows that the response rate was reasonable by the established standards of the expected response rate of $15 \%$ from surveys. All clients had similar veterinary service access because they belonged to VetSouth Ltd at the time of the survey. Therefore, these findings may actually be a true reflection of what clients believed at the time. The result obtained after adjusting for sex, age, and education were not dissimilar to the overall results, suggesting that these factors had no effect on the outcome of the study.

\section{Conclusions}

This study aimed at gaining insight into farmer perception of use and also to determine if there were any barriers to AMU at a farm level. This study showed that farmers were interested in reducing antimicrobial use. Farmers also supported the fact that all prescriptions were supposed to come from veterinarians. Most importantly, farmers relied mostly on veterinary advice for most animal health issues. The area needing more improvements was on milk disposal mechanism on dairy farms. The fact that milk was poured in the drains or fed to livestock increased the risk perpetuating antimicrobial resistance within and between farms. In addition to this, both dairy and sheep farmers either disposed of carcasses on farms or fed to dogs. These practices are not ideal if farmers were going to prevent perpetuating antimicrobial resistance. As other studies have found, policymakers should focus more on credible sources of advice to the farmers to achieve a sustained reduction in AMU. Our research has shown that veterinarians, the livestock industry and peers were the most significant sources of advice. Data regarding suboptimal use of antimicrobials in dairy herds, other livestock, and humans is well established as the driver of antimicrobial resistance in New Zealand and elsewhere. The fact that both dairy and sheep farmers showed varied attitudes towards AMU and AMR suggest that veterinary input is needed to fill up the knowledge gaps.

Supplementary Materials: The following are available online at www.mdpi.com/xxx/s1Table S1: Summary of survey questions. 
Table S1. Summary of survey questions.

\begin{tabular}{|c|c|}
\hline Q1 & $\begin{array}{l}\text { How important are the following factors in influencing how you manage the disease on } \\
\text { your farm? }\end{array}$ \\
\hline Q2 & $\begin{array}{l}\text { How often would you get advice from your vet before deciding how to manage each of the } \\
\text { following problems on your farm? }\end{array}$ \\
\hline Q3 & $\begin{array}{l}\text { What were the biggest problems on your farm over the last } 12 \text { months? A drag the options } \\
\text { to order them from most to least important. Mark an option N/A if you haven't seen it on } \\
\text { your farm in the last } 12 \text { months. }\end{array}$ \\
\hline Q4 & $\begin{array}{l}\text { How effective do you think it would be to use management practices (e.g. nutrition, rest) to } \\
\text { help treat or prevent the following problems? }\end{array}$ \\
\hline Q5 & $\begin{array}{l}\text { How effective do you think it would be to use antimicrobials (antimicrobials - e.g. penicillin) } \\
\text { to help treat or prevent the following problems? }\end{array}$ \\
\hline Q6 & $\begin{array}{l}\text { How effective do you think it would be to use other therapies (e.g. pain killers, an- } \\
\text { ti-inflammatories, vaccinations) to help treat or prevent the following problems? }\end{array}$ \\
\hline Q7 & $\begin{array}{l}\text { How often would you use management practices (e.g. nutrition, rest) to help treat or pre- } \\
\text { vent the following problems? }\end{array}$ \\
\hline Q8 & $\begin{array}{l}\text { How often would you use antimicrobials (e.g. penicillin) to help treat or prevent the follow- } \\
\text { ing problems? }\end{array}$ \\
\hline Q9 & $\begin{array}{l}\text { How often would you use other therapies (e.g. pain killers, anti-inflammatories, vaccina- } \\
\text { tions) to help treat or prevent the following problems? }\end{array}$ \\
\hline Q10 & ch of the following statements, please indicate your level of agreement. \\
\hline Q11 & $\begin{array}{l}\text { What do you do with contaminated meat/carcasses from cows treated with antimicrobials } \\
\text { (i.e. cow that dies or is culled during the withholding period)? If more than one answer is } \\
\text { applicable, select the one you do most often. }\end{array}$ \\
\hline Q12 & $\begin{array}{l}\text { What do you do with penicillin milk (i.e. milk from cows treated with antimicrobials during } \\
\text { the withholding period)? If more than one answer is applicable, select the one you do most } \\
\text { often. }\end{array}$ \\
\hline
\end{tabular}

Author Contributions: “Conceptualization, M.B. and D.M.; methodology, P.M.; software, P.M.; validation, P.M., and S.F.; formal analysis, P.M.; investigation, M.B.; resources, M.B.; data curation, P.M.; writing-original draft preparation, P.M.; writing-review and editing, S.K.; visualization, P.M.; supervision, M.B.; project administration, D.M.; funding acquisition, M.B. All authors have read and agreed to the published version of the manuscript." Funding: This research was funded by The Ministry of Primary Industries, New Zealand, grant number 405327".

Institutional Review Board Statement: “Ethical review and approval were waived for this study, due to REASON (This work was funded and commission by the Ministry of Primary Industries. Since we were using our clients, we were not required to apply for ethics approval if all our clients gave consent before taking the survey. All the respondents were free to stop from completing the survey at any time they so wished. Their details were going to remain anonymous and confidential. Upon providing consent, survey participants also permitted data to be published)." Data Availability Statement: The data generated/ analysed for this work will be available on reasonable request from the author of correspondence. 
Acknowledgments: We are grateful to all the farmers who participated in this study. We are also indebted to all the VetSouth Ltd veterinarians and veterinary technologists for their work with farmers. We are grateful to the Ministry of Primary Industries for funding.

Conflicts of Interest: PM, SF, DM, and MB have no conflicts of interest to declare. The authors declare no competing financial interests..

\section{References}

1. O'Neill, J. 2006. Tackling drug-resistant infections globally: Final report and recommendations. The review on antimicrobial resistance; London: HM Government and the Wellcome Trust. Available online: 46. https://wellcomecollection.org/works/thvwsuba (accessed on 20/02/2021).

2. Robinson, T.P.; Bub, D.P.; Carrique-Masc, J.; Fèvre, E. M.; Gilbert, M.; Grace, D.; Hay, S. I.; Jiwakanon, J.; Kakkar, M.; Kariuki, S.; Laxminarayan, R., Lubroth, J.; Magnusson, U.; Thi Ngoc, P.; Van Boeckel, T. P.; Woolhouse, M. E. J. Antibiotic resistance is the quintessential One Health issue. Trans. R. Soc. Trop. Med. Hyg. 2016, 110, 377-380. https:// doi.org/10.1093/trstmh/trw048.

3. Burgess, S.; French, N. 2017. Antimicrobial resistant bacteria in dairy cattle: A review. New Zealand Food Safety and Science Research Centre, 1-60. https://www.nzfssrc.org.nz/node/79. (accessed on 4/06/2021).

4. Baquero, F.; Garau, J. Prudent use of antimicrobial agents: Revisiting concepts and estimating perspectives in a global world. Enferm. Infecc. Microbiol. Clín. 2010, 28, 487-488. https:// doi.org/ 10.1016/j.eimc.2010.07.009.

5. Chantziaras, I.; Boyen, F.; Callens, B.; Dewulf, J. Correlation between veterinary antimicrobial use and antimicrobial resistance in food-producing animals: a report on seven countries. J. Antimicrob Chemother. 2014, 69,827-834. https://doi.org/10.1093/jac/dkt443.

6. Wernli, D.; Haustein, T.; Conly, J. A call for action: the application of the international health regulations to the global threat of antimicrobial resistance. PLoS Med. 2011, 8,e1001022. https:// doi.org/10.1371/journal.pmed.1001022.

7. Levy, S.B.; Marshall, B. M. Antibacterial resistance worldwide: causes, challenges and responses. Nat. Med. 2004, 10, s122-s129. https://doi.org/10.1038/nm1145.

8. Chauvin, C.; Beloeil, P-A.; Orand, J-P.; Sanders, P.; Madec, F. A survey of group-level antibiotic prescriptions in pig production in France. Prev. Vet. Med. 2002, 55, 109-120. https:// doi.org/10.1016/s0167-5877(02)00091-0.

9. Aarestrup, F.M. Association between the consumption of antimicrobial agents in animal husbandry and the occurrence of resistant bacteria among food animals. Int. J. Antimicrob. Agents 1999, 12, 279-285. doi: 10.1016/s0924-8579(99)90059-6.

10. McDougall, S.; Compton, C.W.R.; Botha, N. Factors influencing antimicrobial prescribing by veterinarians and usage by dairy farmers in New Zealand. N Z Vet. J. 2017, 65, 84-92. https://doi.org/10.1080/00480169.2016.1246214.

11. Morgans, L.; Bolt, C.; Elizabeth, S.B-M.; van Dijk, L.; Escobar, M.P.; Buller, H.J.; Main, D.C.J.; Reyher, K.K. 2021. A participatory, farmer-led approach to changing practices around antimicrobial use on UK farms. J Dairy Scie. 2021, 104, $2212-2230$. https://doi.org/10.3168/jds.2020-18874.

12. Levy, S.B.; Marshall, B. M. Food animals and antimicrobials: impacts on human health. Clin. Microbiol. Rev. 2011, 24,718-33.

13. Chang, Q.; Wang, W.; Regev-Yochay, G. Antibiotics in agriculture and the risk to human health: how worried should we be? Evol. Appl. 2015, 8, 240-245. https:// doi.org/ 10.1111/eva.12185.

14. Messenger, A.M.; Barnes, A.N.; Gray, G.C. Reverse zoonotic disease transmission (zooanthroponosis): a systematic review of seldom-documented human biological threats to animals. PLoS ONE 2014, 9, e89055. https://doi.org/10.1371/journal.pone.0089055.

15. Klous, G.; Huss, A.; Heederik, D.J.J.; Coutinhoa, R. A. Human-livestock contacts and their relationship to transmission of zoonotic pathogens, a systematic review of literature. One Health 2016, 2, 65-76. https://doi.org/10.1016/j.onehlt.2016.03.001.

16. Lazarus, B.; Paterson, D. L.; Mollinger, J. L.; Rogers, B. A. Do human extraintestinal Escherichia coli infections resistant to expanded-spectrum cephalosporins originate from food-producing animals? A systematic review. Clin. Infect. Dis. 2015, 60, 43952. https://doi.org/10.1093/cid/ciu785.

17. Berendonk, T.U.; Manaia, C.M.; Merlin, C.M.; Fatta-Kassinos, D.; Cytryn, E.; Walsh, F.; Bürgmann, H.; Sørum, H.; Norström, M.; Pons, M-N.; Kreuzinger, N.; Huovinen, P.; Stefani, S.; Schwartz, T.; Kisand, V.; Baquero, F.; Martinez, J.L. Tackling antibiotic resistance: the environmental framework. Nat. Rev. Microbiol. 2015, 13, 310-317. https://doi.org/10.1038/nrmicro3439.

18. Kraemer, S.A.; A. Ramachandran, A.; Perron, G. G. Antibiotic Pollution in the environment: from microbial ecology to public policy. Microorganisms 2019, 7-180. https://doi.org/10.3390/microorganisms7060180.

19. Anonymous. 2016. Antibiotic judicious use guidelines for the New Zealand Veterinary profession-Dairy. (Wellington, New Zealand: New Zealand Veterinary Association). https://www.amrvetcollective.com/assets/guidelines/guide_dairy.pdf. (accessed on 20/02/2021).

20. Rizzo, L.; Manaia, C.; Merlin, C.; T. Schwartz, T.; C. Dagot, C.; Ploy, M. C.; Michael, I.; Fatta-Kassinos, D. Urban wastewater treatment plants as hotspots for antibiotic resistant bacteria and genes spread into the environment: a review. Sci. Total Environ. Sci. Total Environ. 2013, 447, 345-360. https://doi.org/10.1016/j.scitotenv.2013.01.032.

21. Boy-Roura M.; Mas-Pla, J.; Petrovic, M.; Gros, M.; Soler, D.; Brusi, D.; Menció, A. Towards the understanding of antibiotic occurrence and transport in groundwater: Findings from the Baix Fluvià alluvial aquifer (NE Catalonia, Spain). Sci. Total Environ. 2018, 612, 1387-1406. https://doi.org/10.1016/j.scitotenv.2017.09.012.

22. Kuipers, A.; Koops, W. J.; Wemmenhove, H. Antibiotic use in dairy herds in the Netherlands from 2005 to 2012 . J. Dairy Sci. 2016, 99,1632-48. https://doi.org/10.3168/jds.2014-8428. 
23. Pol, M.; Ruegg, P.L. Treatment practices and quantification of antimicrobial drug usage in conventional and organic dairy farms in Wisconsin. J. Dairy Sci. 2007, 90, 249-61. https://doi.org/10.3168/jds.S0022-0302(07)72626-7.

24. Saini, V.; McClure, J. T.; Léger, D.; Dufour, S.; Sheldon, A.G.; Scholl, D.T.; Barkema, H.W. Antimicrobial use on Canadian dairy farms. J. Dairy Sci. 2012, 95, 1209-21. https:// doi.org/ 10.3168/jds.2011-4527.

25. Hosoi, Y.; Asai, T.; Koike, R ; Tsuyuki, M.; Sugiura, K. Use of veterinary antimicrobial agents from 2005 to 2010 in Japan. Int. J. Antimicrob. Agents 2013, 41, 489-490. https://doi.org/ 10.1016/j.ijantimicag.2013.01.002.

26. Bryan, M.; Hea S.Y. A survey of antimicrobial use in dairy cows from farms in four regions of New Zealand. $N$ Z Vet. J. 2017, 65: 93-98. https://doi.org/10.1080/00480169.2016.1256794.

27. Likert, R. A Technique for the measurement of attitudes. Arch. Psycholog. 1932, 140, 1-55.

28. R Core Team, 2021. R: A Language and Environment for Statistical Computing. R Foundation for Statistical Computing. https://www.R-project.org/. (accessed on 1/05/2021).

29. Jones P.J.; Marier, E.A.; Tranter, R.B.; Wu, G.; Watson, E.; Teale, C.J. Factors affecting dairy farmers' attitudes towards antimicrobial medicine usage in cattle in England and Wales. Prev. Vet. Med. 2015, 1; 121, 30-40. https://doi.org/10.1016/j.prevetmed.2015.05.010.

30. Cattaneo, A.A.; Wilson, R.; Doohan, D.; LeJeune, J.T. Bovine veterinarians' knowledge, beliefs, and practices regarding antibiotic resistance on Ohio dairy farms. J. Dairy Sci. 2009, 92, 3494-3502. https://doi.org/10.3168/jds.2008-1575.

31. Habing, G., Djordjevic, C., Schuenemann, G.M., Lakritz, J. Understanding antimicrobial stewardship: disease severity treatment thresholds and antimicrobial alternatives among organic and conventional calf producers. Prev. Vet. Med. 2016, 130, 7785. https://doi.org/10.1016/j.prevetmed.2016.06.004

32. Sebastian, G. L-S.; Vezeau, N.; Wemette, M.; Bulut, E.; Safi, A. G.; Moroni, P.; Shapiro, M.A.; Ivanek, R. Survey of perceptions and attitudes of an international group of veterinarians regarding antibiotic use and resistance on dairy cattle farms. Prev. Vet. Med. 2021, 188. https://doi.org/10.1016/j.prevetmed.2020.105253.

33. Vasseur, E.; Borderas, F.; Cue, R.I.; Lefebvre, D.; Pellerin, D.; Rushen, J.; Wade, K.M.; De Passill'e, A.M. A survey of dairy calf management practices in Canada that affect animal welfare. J. Dairy Sci. 2010, 93, 1307-1316. https://doi.org/10.3168/ jds.2009-2429.

34. Coyne, L.A.; Latham, S.M.; Williams, N.J.; Dawson, S.; Donald, I.J.; Pearson, R.B.; Smith, R.F.; Pinchbeck, G.L. Understanding the culture of antibiotic prescribing in agriculture: a qualitative study of UK pig veterinary surgeons. J. Antimicrob. Chemother. 2016, 71, 3300-3312. https://doi.org/10.1093/jac/dkw300.

35. Cobo Angel, C.; Stephen J. LeBlanc, S.J.; Roche, S.M.; Ritter, C. A focus group study of Canadian dairy farmers' attitudes and social referents on antimicrobial use and antimicrobial resistance. Front. Vet. Sci. 2021, 8. doi: 10.3389/fvets.2021.645221.

36. Rogers, G.W.; Van Arendonk, J.A.M.; McDaniels, B.T. Influence of production and prices on optimum culling rates and annualized net revenue. J. Dairy Sci. 1988, 71, 3453-3462. https://doi.org/10.3168/jds.S0022-0302(88)79951-8.

37. Friedman, D.B.; Kanwat, C.P.; Headrick, M.L.; Patterson, N.J.; Neely, J.C.; Smith, L.U. Importance of prudent antibiotic use on dairy farms in South Carolina: a pilot project on farmers' knowledge, attitudes and practices. Zoonoses Public Health 2007, 54, 366-375. https://doi.org/10.1111/j.1863-2378.2007.01077.x.

38. Blake, J. Overcoming the 'value-action gap in environmental policy: tensions between national policy and local experience. Loc. Env. 2009, 4, 257-278. https://doi.org/10.1080/13549839908725599.

39. Lane, B.; Potter, S. The adoption of cleaner vehicles in the UK: exploring the consumer 'attitude-action gap'. J. Clean. Prod. 2007, 15, 1085-1092. https://doi.org/10.1016/j.jclepro.2006.05.026.

40. McIntosh, W.A.; Schulz, S.; Dean, W.; Scott, M.H.; Barling, K.S.; Takei, I. Feedlot veterinarians' moral and instrumental beliefs regarding antibiotic use in feedlot cattle. J. Community Appl. Soc. 2009, 19, 51-67. https://doi.org/10.1002/casp.976.

41. Speksnijder, D.C.; Jaarsma, A.D.C.; Van Der Gugten, A.C.; Verheij, T.J.; Wagenaar, J.A. Determinants associated with veterinary antibiotic prescribing in farm animals in the Netherlands: a qualitative study. Zoonoses Public Health 2015, 62, 39-51. https://doi.org/10.1111/zph.12168.

42. Speksnijder, D.C.; Jaarsma, D.A.; Verheij, T.J.; Wagenaar, J.A. Attitudes and perceptions of Dutch veterinarians on their role in the reduction of antimicrobial use in farm animals. Prev. Vet. Med. 2015, 121, 365-373. https://doi.org/10.1016/j.

43. Higgins, H.M.; Golding, S.E.; Mouncey, J.; Nanjiani, I.; Cook, A.J.C. Understanding veterinarians' prescribing decisions on antibiotic dry cow therapy. J. Dairy Sci. 2017,100, 2909-2916. https://doi.org/10.3168/jds.2016-11923.

44. Hardefeldt, L.Y.; Gilkerson, J.R.; Billman-Jacobe, H.; Stevenson, M.A.; Thursky, K.; Bailey, K.E.; Browning, G.F. Barriers to and enablers of implementing antibiotic stewardship programs in veterinary practices. J. Vet. Intern. Med. 2018, 32, 1092-1099. https://doi.org/10.1111/jvim.15083.

45. Ministry of Health and Ministry for Primary Industries. 2017. Antimicrobial resistance: New Zealand's current situation and identified areas for action. Wellington: Ministry of Health and Ministry for Primary Industries, page 1-31. https://www.health.govt.nz/publication/antimicrobial-resistance-new-zealands-current-situation-and-identified-areas-action (accessed on 10/12/2020).

46. Vaarst, M.; Fisker, I. Potential contradictions connected to the inclusion of stable schools in the legislation for Danish organic dairy farms. Open Agric. J. 2013, 7, 118-124. https://doi.org/ 10.2174/1874331501307010118.

47. Rola, A.C.; Jamias, S.B.; Quizon, J.B. Do Farmer Field School Graduates Retain and Share What They Learn?: An Investigation in Iloilo, Philippines. J. Int. Agric. Ext. Educ. 2002, 9, 65-76. doi: 10.5191/jiaee.2002.09108.

48. Birkhaeuser D.; Evenson R.E.; Feder G. The Economic Impact of Agricultural Extension: A Review. Econ. Dev. Cult. Change 1991, 39; 607-650. https://www.jstor.org/stable/1154389. 
49. Tripp, R.; Wijeratne M.; Piyadasa, V.H. What should we expect from farmer field schools? A Sri Lanka case study. World Dev. 2005, 33, 1705-1720. https://doi.org/10.1016/j.worlddev.2005.04.012. 